\title{
Time Variations in the Composition of Atmospheric Aerosol in Moscow in Spring 2020
}

\author{
D. P. Gubanova ${ }^{a}$ *, A. A. Vinogradova ${ }^{a}$, M. A. Iordanskii ${ }^{b}$, and A. I. Skorokhod ${ }^{a}$ \\ ${ }^{a}$ Obukhov Institute of Atmospheric Physics, Russian Academy of Sciences, Moscow, 119017 Russia \\ ${ }^{b}$ Karpov Institute of Physical Chemistry, Moscow, 105064 Russia \\ *e-mail: gubanova@ifaran.ru
}

Received January 18, 2020; revised February 11, 2021; accepted February 17, 2021

\begin{abstract}
The results of an intensive complex experiment carried out from March 25 to May 3, 2020, to study the composition and time variability of urban aerosol in the atmosphere in the center of Moscow include data on daily mean concentrations of both $\mathrm{PM}_{10}$ and $\mathrm{PM}_{2.5}$ particles and 65 chemical elements. The concentrations of all components did not exceed the maximum permissible concentration (MPC) for residential areas. The exception was increased $\mathrm{PM}_{10}$ concentrations recorded on March 27-29, when air masses from neighboring regions with biomass fires arrived in the city. The coefficients of correlation between values of the concentrations and enrichment factors of the elements confirmed the anthropogenic/local origin of some heavy metals $(\mathrm{Cd}, \mathrm{Sb}, \mathrm{Pb}, \mathrm{Se}, \mathrm{Th})$ and the terrigenous/global origin of elements such as $\mathrm{Mn}, \mathrm{Mg}, \mathrm{Zn}, \mathrm{Co}, \mathrm{Fe}, \mathrm{Al}$, and $\mathrm{Cr}$. The elements $\mathrm{S}, \mathrm{P}, \mathrm{K}, \mathrm{Na}, \mathrm{Ca}, \mathrm{Ni}, \mathrm{Cu}, \mathrm{Mo}, \mathrm{Sn}, \mathrm{W}, \mathrm{Bi}$, and U, for which no significant correlation between their concentrations and enrichment factors has been found, apparently, have a mixed origin from both natural and anthropogenic sources competing with each other from day to day. The first studies of the weekly cycle of the relative elemental composition of surface aerosol in Moscow have shown the leading role of meteorological conditions (in particular, air pressure and humidity) in variations of aerosol pollution levels.
\end{abstract}

Keywords: atmosphere, megacity, Moscow, aerosol, $\mathrm{PM}_{10}$ and $\mathrm{PM}_{2.5}$ particles, mass concentration, elemental composition

DOI: $10.1134 / \mathrm{S} 0001433821030051$

\section{INTRODUCTION}

Aerosol is a variable atmospheric component that significantly and ambiguously affects the climate of different natural zones and areas [1-3]. A variety of aerosols and their effects on the environment and human activities are most pronounced in megacities. The main source of natural aerosols in cities and industrial regions is soil and, to a lesser degree, biomass burning. Primary anthropogenic aerosols are emitted into the atmosphere by industrial enterprises, heat-and-power engineering systems, and transport. Secondary aerosols, which are the fine-dispersed (submicron) aerosol particles, are generated during microphysical and photochemical processes with the participation of water vapor, organic compounds, and different precursor gases. As a result, urban aerosols are variable in their fractional and chemical compositions in both space and time.

In the city, the anthropogenic load on ecosystems is extremely high and often poorly monitored. Some macro- and microelement concentrations increasing up to and above the maximum permissible concentration (MPC) may be hazardous for the links of the tro- phic chain-from soil, water bodies, vegetation, and animals all the way up to humans [4]. On the other hand, data on the elemental composition of aerosol are especially important as indirect evidence of local and remote sources of atmospheric pollution and its way to the observation site [5]. To solve such problems, some tracers (concentrations of some chemical elements and their ratios), which are characteristic of the composition of substances emitted into the atmosphere during any human or natural activity (different production operations, transport, volcanoes, fires, etc.), are analyzed [6-13].

These two aspects (concentration levels of different components and possibilities to reveal pollution sources) determine the interest in a complex object of air medium such as the elemental composition of aerosol. However, studying the elemental composition of aerosol particles is a very labor-consuming process which requires that experiments be conducted with a high degree of accuracy and an expensive analysis of aerosol samples. This apparently explains the fact that there are few publications on the elemental composition of aerosol in the domestic literature. We can cite some papers devoted to the study of the elemental com- 
position of aerosols in desertificated areas [12, 14, 15], remote Arctic areas [16-18], Siberian cities [19-21], and other areas [22, 23]. As for the atmosphere over the Moscow region, the elemental composition of aerosols there has been studied only occasionally, and there are few papers on this topic [24-29]. In recent years, some papers devoted to the study of the elemental composition of solid road-dust particles and aerosols in the atmosphere over the Moscow megacity have been published [30-32].

New data on the elemental composition of aerosol in the urban air of the megacity, which have been obtained in the course of an intensive complex experiment carried out by the Obukhov Institute of Atmospheric Physics (OIAP), Russian Academy of Sciences, in the center of Moscow, are given in this work. Time variations in the elemental composition of aerosol samples are considered in comparison with the disperse composition of aerosol, meteorological conditions, and directions of long-range air-mass transport; some groups of elements of different geneses have been revealed.

\section{INSTRUMENTS TO TAKE AND ANALYZE AEROSOL SAMPLES}

The mass concentration of aerosol particles of sizes smaller than $10 \mu \mathrm{m}\left(\mathrm{PM}_{10}\right)$ and $2.5 \mu \mathrm{m}\left(\mathrm{PM}_{2.5}\right)$ is determined daily by a numerical method [1] using microparticle number concentrations measured in a continuous automatic mode with the aid of both LAS-P laser and OEAS-05 optical-electrical aerosol spectrometers (with a time resolution of $5 \mathrm{~min}$ ) developed at the Karpov Institute of Physical Chemistry [15]. These instruments are installed in the courtyard of the OIAP located in the center of Moscow (Pyzhevskii per., 3). The observation site is in the administrative center of the city in the vicinity of motorways with medium and light traffic loads, but away from industrial and power enterprises. The main local pollution sources are associated with motor transport. The OIAP courtyard is small and is also used as a parking place for up to ten personal vehicles. It is separated from city streets by a fence and auxiliary brick low-rise buildings, which may decrease the emissions of large aerosol particles from the underlying surface due to transport activity.

The atmospheric composition is intensively monitored in each season for $1-1.5$ months, when the mass concentration of total aerosol precipitated onto an AFA-type filter with the aid of aspiration samplers for $24 \mathrm{~h}$ (from 9:00 to 9:00 next day) is additionally measured using the gravimetrical method. The same daily samples are used to study the elemental composition of aerosol using the method of inductively coupled plasma mass spectrometry [33]. Aerosol samples for both gravimetrical and chemical analyses are taken at a height of $2 \mathrm{~m}$ above the land surface.
Within the periods of intensive monitoring, aerosol samples are continuously taken onto hydrophobic filters made of the Petryanov cloth and AFA-WP-10 analytical filters with the aid of a six-cascade impactor. These samples are used to study the mean size distribution of aerosol particles and chemical elements contained in them also using both gravimetrical and inductively coupled plasma mass spectrometry methods [33].

Data on meteorological parameters obtained with a time interval of $3 \mathrm{~h}$ at the Balchug station (Srednii Ovchinnikovskii per., 1, str. 1) located $800 \mathrm{~m}$ northeast of the OIAP observation point have been taken from open Internet sources [34]. In the course of the intensive experiment, both synoptical and meteorological conditions were analyzed using the Internet [35] and the method of backward air-mass moving trajectories calculated with the aid of the NOAA HYSPLIT model [36].

In this work, data obtained from the intensive aerosol composition monitoring carried out from March 25 to May 3, 2020, are analyzed. This observation period coincided with the start of restrictive measures taken in Moscow to prevent the spread of the coronavirus, which resulted in a decrease in the anthropogenic impact on the urban environment in spring 2020.

\section{RESULTS}

\subsection{Disperse Composition of Aerosol}

Figures $1 \mathrm{a}$ and $1 \mathrm{~b}$ show the dependences of the total mass $M$ of aerosol composed of particles of the three fractions-fine dispersed $\left(\mathrm{PM}_{2.5}\right)$, micron (2.5$10 \mu \mathrm{m})$, and coarse $(>10 \mu \mathrm{m})$-from sample to sample within 40 days of the intensive monitoring in spring 2020 . It is seen that the variations in the total concentration of aerosol and its disperse composition were significant within this period; however, its components rarely exceeded the MPC (Fig. 1c).

On the first 5 days of the period under consideration, high aerosol concentrations (exceeding the MPC for $\mathrm{PM}_{10}$ ) were due to the atmospheric transport of dust and biomass burning aerosols from areas of spring grass fires (Fig. 2) in Tver, Pskov, Smolensk, Tula, Kaluga, and Ryazan oblasts [37]. Numerous stations of Budgetary Environmental Protection Institution "MOSECOMONITORING" also recorded maximum air pollution caused by aerosol particles in late March 2020. In particular, data obtained at the Spiridonovka station (nearest to the OIAP station) [38] were in good agreement with data obtained at the OIAP station for $\mathrm{PM}_{10}$ and $\mathrm{PM}_{2.5}$ [39]. On all the other days, under sufficiently cool spring weather conditions with light wind and light precipitation (meteorological data are given below), aerosol concentrations were low.

The long-range transport of aerosol to Moscow was analyzed using backward air-mass moving trajectories calculated with the aid of the HYSPLIT model [36] on the NOAA ARL website [40] for each daily aerosol sample (according to eight $72-\mathrm{h}$ trajectories con- 

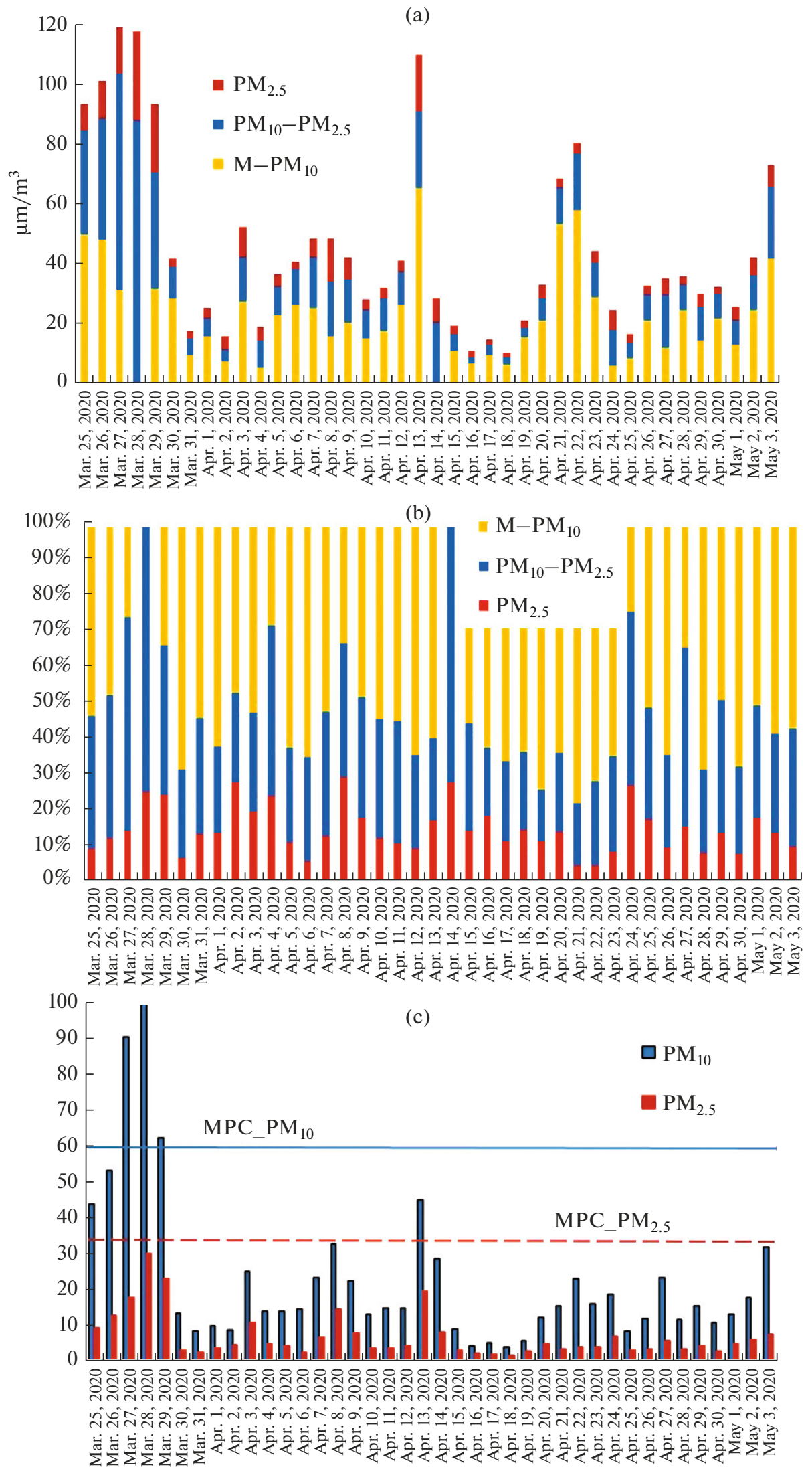

Fig. 1. Daily mean mass concentrations of aerosol particles: ratios in the total aerosol mass $M$ between the masses of large aerosol particles $\left(\mathrm{M}-\mathrm{PM}_{10}\right)$ and particles of micron $\left(\mathrm{PM}_{10}-\mathrm{PM}_{2.5}\right)$ and fine-dispersed $\left(\mathrm{PM}_{2.5}\right)$ fractions in (a) absolute and (b) relative units. (c) $\mathrm{PM}_{10}$ and $\mathrm{PM}_{2.5}$ particle fractions; the horizontal lines correspond to the levels of their daily mean MPCs. 
(a)

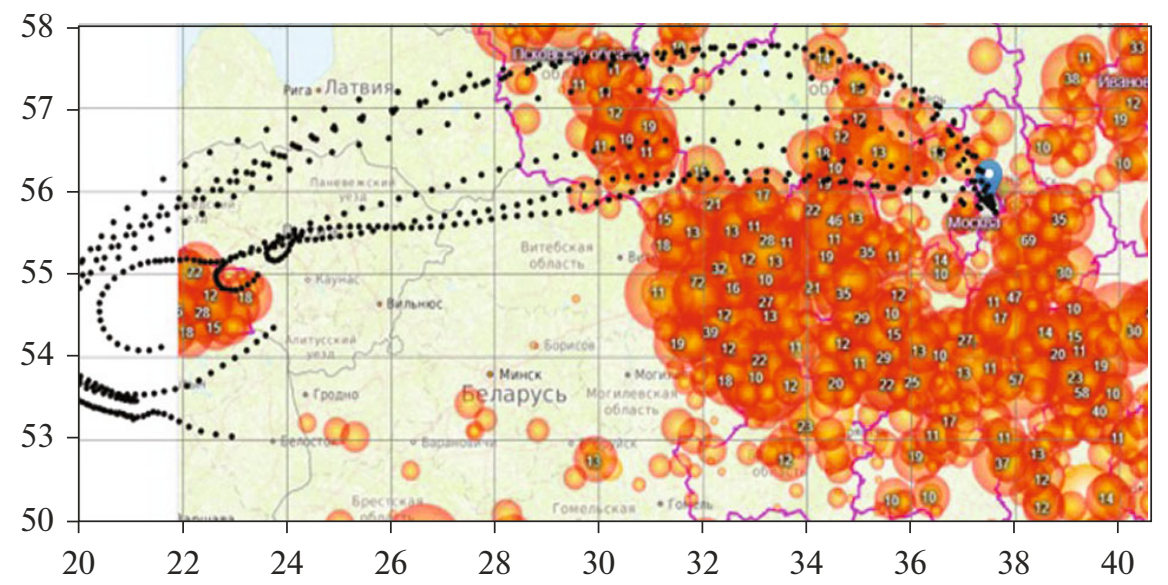

(b)

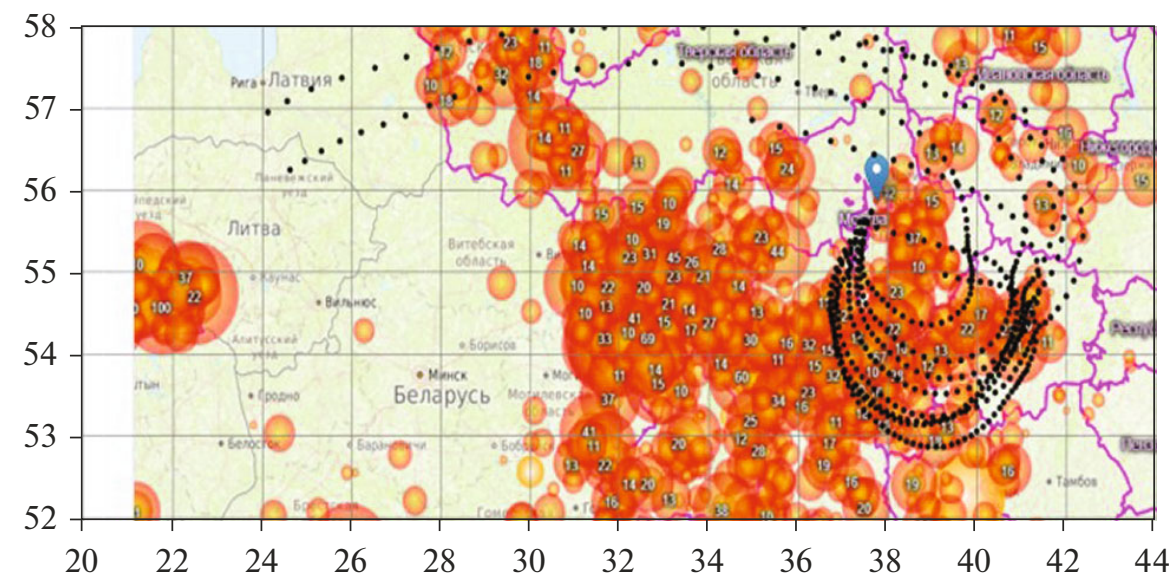

Fig. 2. Location of the fires (red circles) and trajectories of air transport (sequences of black points) towards Moscow: (a) March 26 and (b) March 28. The vertical and horizontal scales correspond to the northern latitude and east longitude, respectively, in degrees.

structed in $3 \mathrm{~h}$ for a height of $100 \mathrm{~m}$ ). As an example, Fig. 2 shows the distributions of the trajectories of transport of air masses and seats of fires (according to data given in [37]) for March 26 and 28, 2020, which demonstrate the probable sources of aerosols that arrived on these days in the atmosphere of Moscow from regions with biomass fires.

Table 1 gives the means of total mass $M$, the masses of $\mathrm{PM}_{10}$ and $\mathrm{PM}_{2.5}$ particles, their rms (standard) deviations, and the medians for the whole period under consideration (March 25-May 3, 2020) and for this period without the first 5 days. The means of $M, \mathrm{PM}_{10}$, and $\mathrm{PM}_{2.5}$ for the first 5 days were 2.9, 4.6, and 3.7 times higher, respectively, than those for the remaining 35 days. These values and the data given in Table 1 imply that the episode of March 25-29 is anomalous when compared to the remaining days, which makes it possible to focus our attention individually on the episode of the maximum atmospheric aerosol pollution or, on the contrary, to exclude these 5 days from the analysis.

\subsection{Elemental Composition of Aerosol}

General statistics and variety of the elemental composition of aerosol. In total, 65 chemical elements (from Li to U) were determined in aerosol samples. For the most illustrative presentation of the results, we will consider the 25 chemical elements given in Table 2 in the form of their monthly mean concentrations, relative standard deviations of their daily mean concentrations, and enrichment factors (EFs) of their monthly means. Note that all daily mean values are lower than the levels of the corresponding MPCs for the air in cities. Even on March 27 (sample 3), when the content of aerosol in the atmosphere in the center of Moscow was maximal (Fig. 1a), only the daily mean concentrations of $\mathrm{Fe}$ and $\mathrm{Ca}$ were almost at their MPC levels.

These 25 elements were conventionally divided into four groups (Table 2): globally distributed ele- 
Table 1. Statistical indicators of the aerosol mass concentration $\left(\mu \mathrm{m} / \mathrm{m}^{3}\right)$ for the entire period under consideration and for 35 days without the episode of maximum air pollution in March

\begin{tabular}{l|c|c|c|c|c|c}
\hline \multicolumn{1}{c|}{ Indicator } & \multicolumn{2}{|c|}{$M$} & \multicolumn{2}{c}{$\mathrm{PM}_{10}$} & \multicolumn{2}{c}{$\mathrm{PM}_{2.5}$} \\
\hline \multicolumn{1}{c|}{ Period } & $\begin{array}{c}\text { March 25 } \\
\text { to May 3 }\end{array}$ & $\begin{array}{c}\text { March 30 } \\
\text { to May 3 }\end{array}$ & $\begin{array}{l}\text { March 25 } \\
\text { to May 3 }\end{array}$ & $\begin{array}{c}\text { March 30 } \\
\text { to May 3 }\end{array}$ & $\begin{array}{l}\text { March 25 } \\
\text { to May 3 }\end{array}$ & $\begin{array}{c}\text { March 30 } \\
\text { to May 3 }\end{array}$ \\
\hline Mean & 44.8 & 36.4 & 23.1 & 15.8 & 6.7 & 5.0 \\
Rms deviation & 30.3 & 21.4 & 23.2 & 8.9 & 6.2 & 3.6 \\
Median & 35.7 & 32.9 & 14.6 & 13.9 & 4.2 & 3.9 \\
\hline
\end{tabular}

Table 2. Some statistical indicators of the concentrations of the chemical elements under consideration in Moscow atmosphere in spring 2020: mean concentration $C$, relative standard deviation (RSD) of daily means, enrichment factor EF of monthly mean concentration in relation to the earth's crust composition, and the correlation coefficients $\mathrm{R}$ between daily mean concentrations $C$ and enrichment factors for 40 days

\begin{tabular}{|c|c|c|c|c|c|c|}
\hline \multicolumn{2}{|c|}{ Elements } & $\mathrm{C}, \mu \mathrm{m} / \mathrm{m}^{3}$ & $\mathrm{RSD}, \%$ & EF & $\mathrm{R}(\mathrm{C}-\mathrm{EF})$ & Comments \\
\hline \multirow{8}{*}{ GDEs } & $\mathrm{Al}$ & 0.76 & 73 & 0.4 & -0.30 & \multirow{8}{*}{$\begin{array}{l}\text { Terrigenous ( } \mathrm{Al} \text { and } \mathrm{La} \text { ), mainly } \\
\text { marine ( } \mathrm{Na}, \mathrm{Mg}, \mathrm{K} \text {, and } \mathrm{Ca} \text { ) ele- } \\
\text { ments, as well } \mathrm{S} \text { and } \mathrm{P} \text { (which have } \\
\text { a lot of different natural and } \\
\text { anthropogenic sources) }\end{array}$} \\
\hline & $\mathrm{P}$ & 0.046 & 79 & 2.3 & -0.13 & \\
\hline & S & 0.45 & 70 & 45 & -0.15 & \\
\hline & $\mathrm{Na}$ & 0.40 & 73 & 0.7 & 0.08 & \\
\hline & $\mathrm{Mg}$ & 0.39 & 72 & 1.0 & -0.48 & \\
\hline & $\mathrm{K}$ & 0.29 & 68 & 0.5 & -0.21 & \\
\hline & $\mathrm{Ca}$ & 2.5 & 86 & 4.0 & 0.15 & \\
\hline & $\mathrm{La}$ & 0.00062 & 82 & 1.0 & & \\
\hline \multirow{5}{*}{ THMs } & $\mathrm{Cr}$ & 0.0033 & 83 & 1.8 & -0.27 & \multirow{5}{*}{$\begin{array}{l}\text { Elements slightly enriched in rela- } \\
\text { tion to the earth's crust }(\mathrm{EF}<10) \text {. }\end{array}$} \\
\hline & Mn & 0.024 & 76 & 1.1 & -0.50 & \\
\hline & $\mathrm{Fe}$ & 1.2 & 83 & 1.2 & -0.32 & \\
\hline & Co & 0.00058 & 79 & 1.5 & -0.36 & \\
\hline & $\mathrm{Ni}$ & 0.0019 & 92 & 1.6 & 0.02 & \\
\hline \multirow{10}{*}{ AHMs } & $\mathrm{Cu}$ & 0.013 & 102 & 13 & -0.02 & \multirow{10}{*}{$\begin{array}{l}\text { Elements of mainly anthropogenic } \\
\text { origin EF }>10 \text {. }\end{array}$} \\
\hline & $\mathrm{Zn}$ & 0.040 & 70 & 23 & -0.39 & \\
\hline & $\mathrm{Se}$ & 0.00029 & 74 & 272 & 0.27 & \\
\hline & Mo & 0.00036 & 111 & 15 & 0.07 & \\
\hline & $\mathrm{Cd}$ & 0.00020 & 98 & 70 & 0.34 & \\
\hline & Sn & 0.0018 & 130 & 33 & 0.26 & \\
\hline & $\mathrm{Sb}$ & 0.0013 & 137 & 129 & 0.48 & \\
\hline & $\mathrm{W}$ & 0.00066 & 87 & 23 & 0.17 & \\
\hline & $\mathrm{Pb}$ & 0.0078 & 104 & 22 & 0.47 & \\
\hline & $\mathrm{Bi}$ & $8.3 \mathrm{E}-05$ & 126 & 429 & 0.18 & \\
\hline \multirow{2}{*}{ REs } & Th & 0.00014 & 82 & 0.5 & 0.31 & \multirow{2}{*}{ Radioactive elements } \\
\hline & $\mathrm{U}$ & $5.1 \mathrm{E}-05$ & 80 & 0.9 & 0.20 & \\
\hline
\end{tabular}

$\mathrm{EF}>10$ and the reliable values of $\mathrm{R}$ for 40 pairs of values are in bold type.

ments (GDEs), heavy metals and metalloids of mainly terrigenous (THMs) or anthropogenic (AHMs) origin, and radioactive elements (REs). A few radioactive elements, lanthanides, rare-earth elements, and others were also considered in the initial analysis. The variations in the concentrations of all these elements from sample to sample were similar to those in terrigenous GDEs ( $\mathrm{Al}$ and $\mathrm{La}$ ).

The elements were divided into groups on the basis of data on the origin of different chemical elements precipitated on atmospheric aerosol particles [9, 41, 

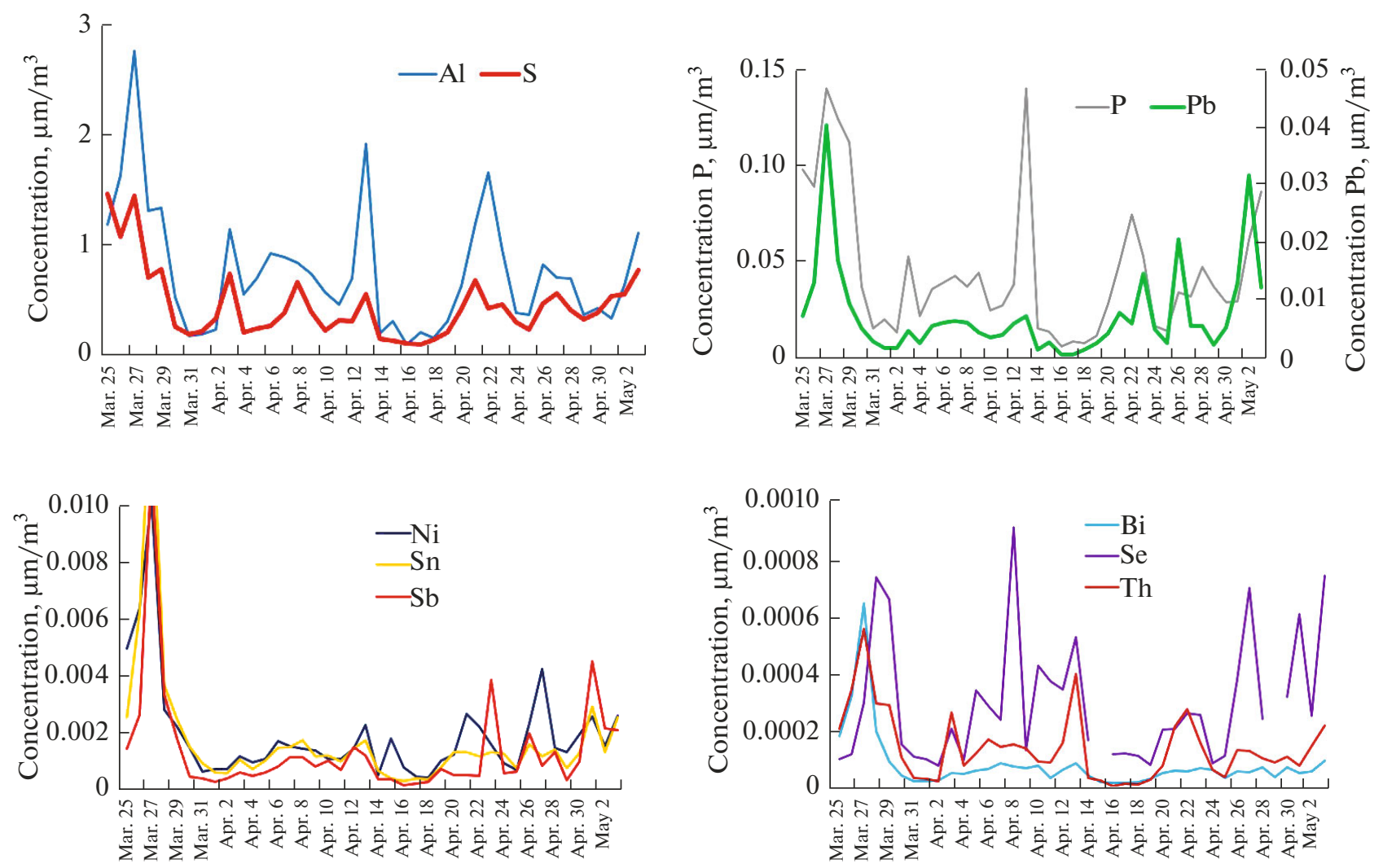

Fig. 3. Variations in the daily mean concentrations of some elements from day to day within the observation period.

42] and in accordance with their EFs with respect to the earth's crust composition [43-45] (the reference element of terrigenous origin La and data on the mean composition of the earth's crust were taken from [46]). Recall that the enrichment factor of elements $\mathrm{EF}_{\mathrm{el}}$ is calculated using concentrations $C$ as follows: $\mathrm{EF}_{\mathrm{el}}=$ $\left(C_{\mathrm{el}} / C_{\mathrm{La}}\right)^{\text {sample }} /\left(C_{\mathrm{el}} / C_{\mathrm{La}}\right)^{\text {earth crust }}$. The elements with $\mathrm{EF}>10$ in urban aerosol are usually considered anthropogenic. Sulfur (S) is assigned to the group of GDEs because of the scale of its ecological effect on the environment [42] and its high concentration in the atmosphere over Europe due to emissions from industrial enterprises in the form of gaseous sulfur dioxide $\left(\mathrm{SO}_{2}\right)$ rapidly transforming into different sulfates on aerosol particles [45].

Figure 3 gives a few contrast time dependences of the concentrations of some elements from the abovementioned groups for the observation period. For convenience of presentation, the elements in the diagrams are combined not by the similarity of the dependences, but by their concentration values. It is seen that all the dependences are maximum on the first 5 days (the maximum pollution episode) and may significantly differ from those on the remaining days of the spring period under consideration.

Correlation between concentration values of different elements in the atmospheric aerosol of Moscow. The presence of significant correlations between concentration values of some elements from sample to sample may imply their common origin. However, at the same time, this may reflect the common generation of these elements in some processes (common genesis) and the similarity in the directions of transport of elements of quite different origins in air flows arriving at the observation point (common atmospheric transport of elements and their closely located sources).

The threshold of the statistical significance of correlation coefficient $N$ for pairs of values at the $95 \%$ confidence level is determined from the formula $R_{N}=$ $2(\mathrm{~N}-2)^{-0.5}$ [47] (for 40 pairs of values $\mathrm{R}_{40}=0.32$ ). An analysis of the pairwise correlation between daily mean concentrations of the elements shows their possible relations schematically presented in Fig. 4.

GDEs: $\mathrm{Al}, \mathrm{Mg}, \mathrm{K}, \mathrm{Ca}$, and $\mathrm{La}$ are strongly related ( $\mathrm{R}>0.95) ; \mathrm{P}$ is related to $\mathrm{Al}(0.9<\mathrm{R}<0.95)$; and $\mathrm{S}$ and $\mathrm{Na}$ are more weakly related to this group $(\mathrm{R}<0.9)$. By the character of their interdiurnal concentration variability in the air, REs with correlation coefficients $\mathrm{R}>0.9$ may also join this group.

THMs: All elements except for $\mathrm{Ni}$ are strongly related, which may be due to their mainly terrigenous nature (dust and soil). $\mathrm{Ni}$ is more weakly related to them, especially to $\mathrm{Mn}(\mathrm{R}<0.9)$. 

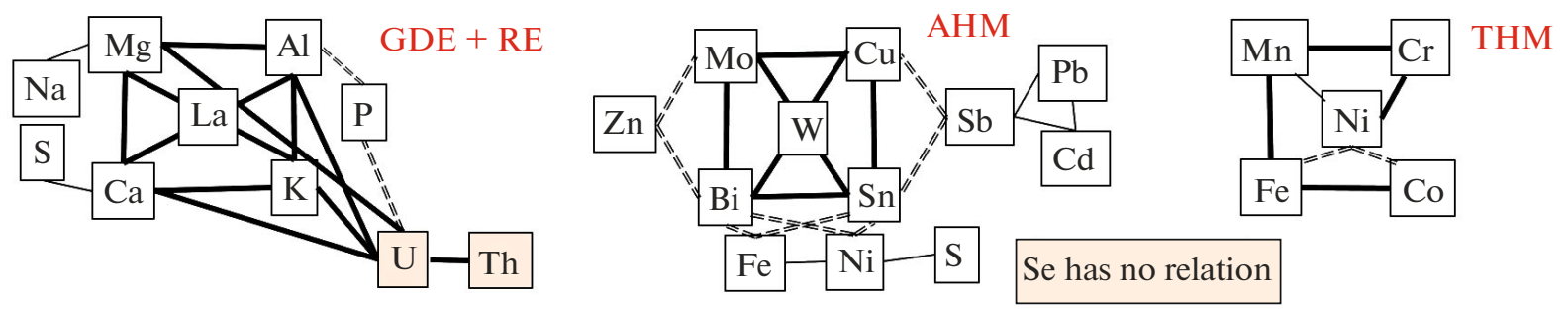

Fig. 4. Relations between the elements according to the value of the Pearson coefficient R of pair correlation of their interdiurnal concentration variations. The thick lines correspond to $\mathrm{R}>0.95$, the thin lines correspond to $\mathrm{R} \approx 0.85$, and the dashed lines correspond to $0.85<\mathrm{R}<0.95$.

AHMs: $\mathrm{Cu}, \mathrm{Mo}, \mathrm{Sn}, \mathrm{W}$, and $\mathrm{Bi}$ are strongly related $(\mathrm{R}>0.95) ; \mathrm{Zn}$ and $\mathrm{Sb}$, with smaller correlation coefficients $(0.9<\mathrm{R}<0.95)$, also belong to this group. $\mathrm{Pb}$ forms a group with $\mathrm{Cd}$ and $\mathrm{Sb}$ with correlation coefficients $(0.82<\mathrm{R}<0.85)$; Se is related almost to nothing $(\mathrm{R}<0.4)$. Bi and $\mathrm{Sn}$ form a group strongly related to $\mathrm{Fe}(\mathrm{R}>0.9)$; $\mathrm{Ni}(\mathrm{R}$ is slightly higher than 0.9$)$ and its related sulfur also join them.

REs: They are strongly related to one another $(\mathrm{R}>$ 0.98 ) and, as was noted above, to the main GDE group.

Distribution of elements according to the size of aerosol particles. Aerosol particles during their atmospheric transport precipitate onto the surface due to the mechanisms of dry deposition and washout by precipitation. In this case, the largest and heaviest particles are removed from air flows faster than small ones. Therefore, in the general case, the EFs of chemical elements transported mainly on small aerosol particles should be higher on a global scale, which was noted earlier in [41, 48]. The EF values may become higher for anthropogenic elements, whose sources are in the vicinity of observation points, in particular, in cities and large industrial regions. Within the entire period of intensive monitoring, a six-cascade impactor collected aerosol particles of different sizes: $<0.5,0.5-1.5$, $1.5-2.5,2.5-4.0,4.0-6.5$, and $>6.5 \mu \mathrm{m}$ for each cascade, respectively, to analyze their elemental composition. The distribution of the mass of the elements under study, according to the size of aerosol particles (for the entire observation period), is shown in Fig. 5. The elements are arranged according to their increasing mass on $\mathrm{PM}_{2.5}$ aerosol particles (total mass of the smallest particles for three cascades of the impactor; see the legend in Fig. 5).

It is seen that the elements are divided into those whose mass concentrated on $\mathrm{PM}_{2.5}$ aerosol particles (total mass of the smallest particles for the three cascades) is smaller (to the left of $\mathrm{Bi}$ ) or larger (to the right of $\mathrm{Bi}$, starting from $\mathrm{Bi}$ ) than $50 \%$. Correspondingly, almost all GDEs, REs, and THMs are in the left-hand side of the diagram and mainly AHMs are in its righthand side. The exceptions are W, Sn (on larger particles) and $\mathrm{K}, \mathrm{S}$ (on small particles). One may suggest the presence of local sources of tungsten and tin in the city and, conversely, mainly the atmospheric long-range transport of sulfur and potassium or their generation in the urban atmosphere during gas-phase reactions.

\subsection{Elemental Composition of Aerosol and Meteorological Parameters}

Weekly cycle. Like any megacity, Moscow has its own activity rhythms, the most noticeable of which is determined by working hours of the bulk of the population, many industrial enterprises, and institutions (weekly cycle). The observation period under consideration includes only five full weeks. Since the number of weeks is small, the first five aerosol samples with anomalously high concentrations of almost all components have been excluded from calculations to try to reveal mean (of five values) dependences of element concentrations on the day of the week under the least disturbed conditions. As a result, a few characteristic time dependences of the concentrations of chemical elements in the air of Moscow within a week have been found: $\mathrm{Ni}, \mathrm{Al}$, and $\mathrm{P}$ decrease from Monday to Sunday and are minimum on Saturday; Sn and $\mathrm{S}$ have no trend and are maximum on Friday; Th and Se have no trend but increase on Wednesday and Friday; and $\mathrm{Pb}$ and $\mathrm{Sb}$ with a positive trend and minimum on Wednesday. Figure 6a shows five characteristic types of the weekly dependences of the concentrations of the elements.

The weekly cycles of the concentrations of some elements, which are given as an example in Fig. 6a, easily demonstrate that the relative aerosol composition is quite different on different days of the week. It is possible that the aerosol composition is formed by both local and remote sources of the elements under consideration. However, it should be noted that meteorological conditions also affect time variations in concentrations of aerosol as a whole and its individual elements. It is known that, in Moscow, the characteristic period of the change of baric formations lasts for 5 to 7 days, and, within the observation period under consideration (40 days), increased pressure $(p)$ was observed on Sunday, Monday, and Tuesday (Fig. 6b). In this case, the anticyclonic conditions corresponded 


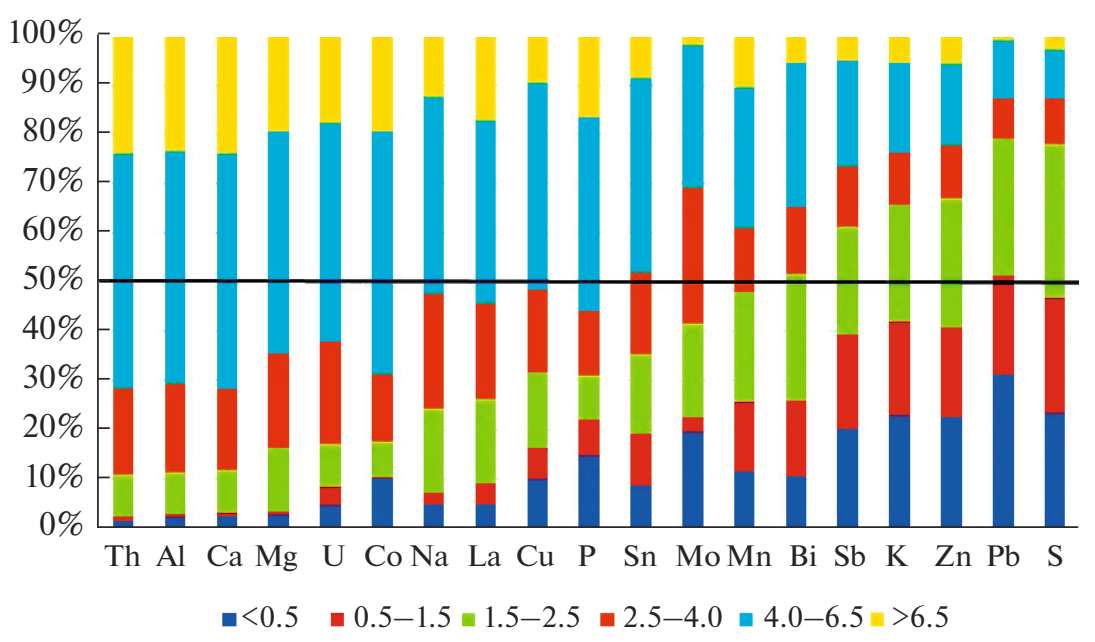

Fig. 5. Distribution of the mass of the elements according to the size of aerosol particles. The legend is the range of aerosol particle sizes in the impactor cascades, $\mu \mathrm{m}$. The horizontal line corresponds to the level of the half-mass of each element.

to higher air temperatures and lower air humidity $(U)$ and favored the accumulation of pollutants in the atmospheric surface layer. A decrease in air pressure in the middle of the week caused an increase in atmospheric vertical mixing, humidity, and precipitation, which favored atmospheric purification (Table 3 and

(a)

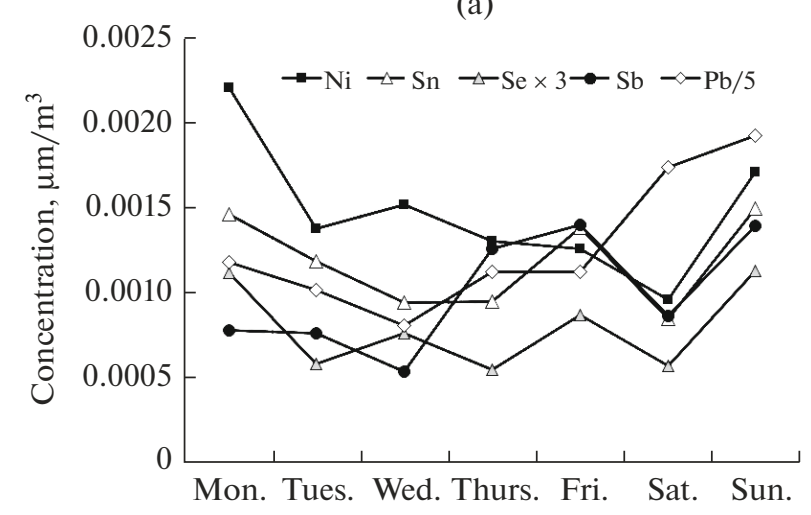

(b)

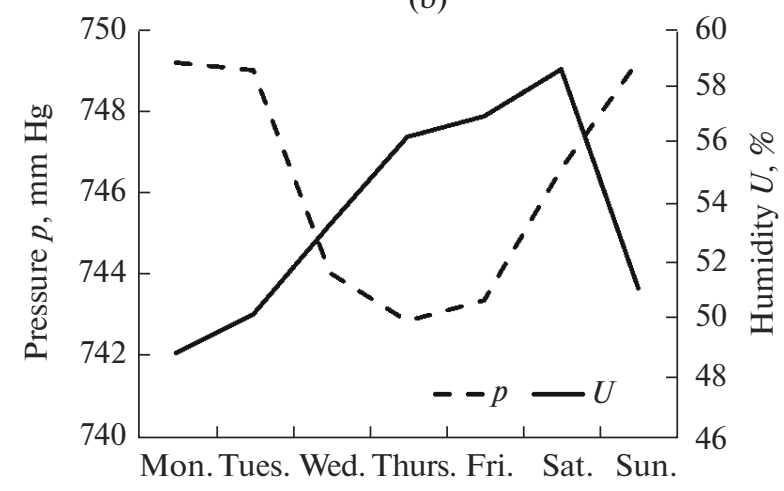

Fig. 6. Weekly cycles (5 weeks) of (a) the concentrations of some elements (those for $\mathrm{Se}$ and $\mathrm{Pb}$ are scaled to fit the figure) and (b) the pressure $P$ and relative humidity $U$ of the air.
Fig. 7). Such a sufficiently high negative correlation between the aerosol mass and humidity (Table 3) suggests the determining role of the process of precipitation of aerosol in its concentration variations. Thus, in Fig. 6a, all the curves show that the concentrations increased on Sunday, when compared to Saturday, and Fig. $6 \mathrm{~b}$ shows that the air humidity variations have quite an opposite character on these days.

In Fig. 7, the singled-out three points for $\mathrm{PM}_{10}$ and three points for $\mathrm{PM}_{2.5}$ correspond to the aerosol samples of March 27-29, when the air in Moscow was heavily polluted with biomass burning aerosols arrived from the areas of spring grass fires (Fig. 2). In addition, there were unfavorable meteorological conditions in Moscow-high pressure, low humidity, and the calm conditions amounted to $35 \%$ for the first 5 days (at $15 \%$ for the 40 days under consideration). These days, pollutants accumulated in the surface air and the atmospheric pollution index increased.

Note that on Sundays and Mondays, at almost the same values of high pressure and low humidity, the concentrations of some elements vary: the concentrations of $\mathrm{Ni}, \mathrm{Al}$, and $\mathrm{P}$ increase, and the concentrations of $\mathrm{Pb}$ and $\mathrm{Sb}$ decrease. This may be interpreted as follows: the elements of global distribution accumulate in the air under unfavorable meteorological conditions, and the elements of local origin may decrease their concentrations with decreased emissions from their sources. For anthropogenic $\mathrm{Pb}$ and $\mathrm{Sb}$, whose main source in the city is transport [30], a decrease in their source on days off is natural. However, for now, this is only a hypothesis.

Thus, based on data obtained within such a short observation period (5 weeks), the analysis of weekly variations in the atmospheric pollution of the city did not allow one to reliably separate the effects of meteorological conditions and local sources on the forma- 
tion of the elemental composition of aerosols. It is necessary to continue observations and analyze the elemental composition of aerosols in Moscow in other seasons and other years, when the activity of some anthropogenic pollution sources is not intentionally weakened (transport and industrial enterprises) by artificial restrictions associated with measures taken to prevent the spread of viral infections.

Correlation between concentrations of some elements and their EFs. It is interesting that, for some elements, significant coefficients of correlation between their daily mean concentrations and EFs (bold type in Table 2) have been revealed based on calculations using 40 aerosol samples. In this case, the correlation is positive for some $\mathrm{AHMs}-\mathrm{Pb}, \mathrm{Sb}$, and $\mathrm{Cd}$ (the correlation coefficients for Se and Th are slightly below the significance threshold) - and negative for some THMs and GDEs-Mn, Mg, Zn, and Co (the correlation coefficients for $\mathrm{Fe}, \mathrm{Al}$, and $\mathrm{Cr}$ are slightly below the significance threshold). For clarity, Fig. 8 shows the weekly relations between the concentrations and EFs for some elements.

Thus, the fact that the dominating origin of the corresponding urban chemical elements in the city in spring is of anthropogenic/local or terrigenous/global character (at positive or negative correlation between their concentrations and EFs) is supported once again. One may suggest that elements for which no reliable correlation between their concentrations and EFs have been found originate from both natural and anthropogenic sources, whose contributions are comparable and compete with one another on different days.

Concentrations of elements, wind direction, and airmass transport. Since one of the mechanisms of formation of aerosol fields in the surface atmosphere is atmospheric transport of different scales, the winddirection dependences of the elemental composition of aerosols have been considered. Such dependences are given for some elements in Fig. 9. The daily mean wind direction is calculated from standard meteorological measurements every $3 \mathrm{~h}$ at the Balchug station.

Note that wind direction is not the direction at which an air mass and its composition form. In this case, it is just the direction of wind at which mean concentrations of elements have certain values. Air masses are usually transported along no straight paths, which is easily seen in Fig. 2, because the wind field on a regional scale forms due to the distribution of atmospheric cyclones/anticyclones. Searching for sources of any air pollutant according to wind direction, one should be oriented only to the nearest local pollutant sources. Therefore, in Fig. 9, the wind direction dependences of GDEs and THMs are more smoothed than those of AHMs, whose point sources may be within the megacity. The distribution of the total aerosol mass (which is determined by elements with maximum masses (Table 2)) according to wind direction qualita-

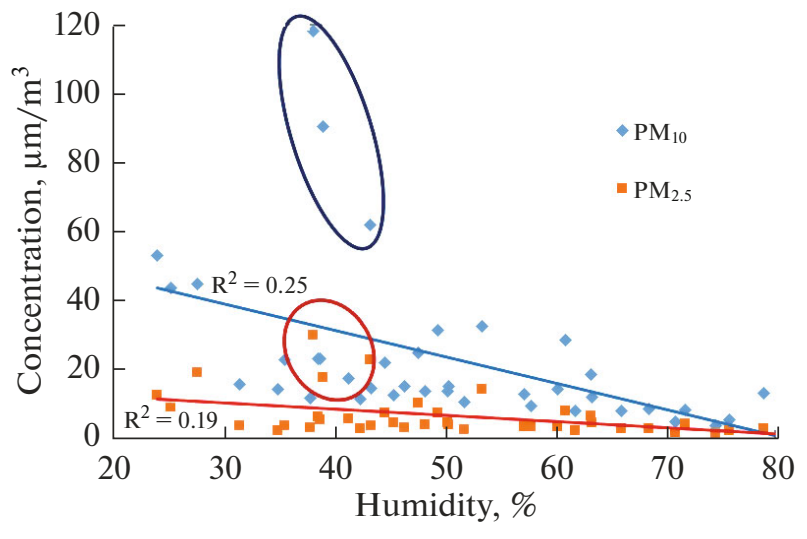

Fig. 7. Dependences of the mass concentrations of the $\mathrm{PM}_{10}$ and $\mathrm{PM}_{2.5}$ aerosol particles on air humidity within the 40-day period under consideration. The points of the anomalously polluted atmosphere, which correspond to March 27, 28, and 29, are singled out.

tively corresponds to GDE distributions (for example, the distribution of $\mathrm{Mg}$ in Fig. 9).

When comparing wind directions with data obtained from an analysis of long-range transport of air masses according to their backward trajectories, one can single out the following regularities for the 40 days under consideration in spring 2020. Depending on speed, northerlies could transport air masses to Moscow from areas of the Kola Peninsula, Scandinavia, Arkhangelsk oblast, and further to the northeast. Easterlies brought air masses from both southern and southeastern regions during the cyclone and brought air masses from northeastern to northwestern regions during the anticyclone. Winds from both southern and southeastern directions could bring air masses to Moscow from southeastern regions up to Kalmykia and the Caspian region. Both southwesterlies and westerlies could bring air masses to Moscow from western and northwestern regions, including Belarus, the Baltic states, and St. Petersburg. Both westerlies and northwesterlies cover a very wide sector of possible areas of influence-from northwestern Russia to Ukraine, Belarus, and the Baltic states. Revealing the influence of different areas and their sources on the aerosol composition in Moscow is one of the tasks of further studies of the elemental composition of aerosol in the city.

Table 3. Pearson pair correlation coefficients for air pressure $p$, relative humidity $U$, air temperature $T$, and total aerosol mass $M$ (for all 40 daily means of each parameter)

\begin{tabular}{l|c|c|c|c}
\hline & $p$ & $U$ & $T$ & $M$ \\
\hline$p$ & 1 & & & \\
$U$ & -0.57 & 1 & & \\
$T$ & 0.10 & -0.52 & 1 & \\
$M$ & 0.53 & $\mathbf{- 0 . 7 0}$ & 0.57 & 1 \\
\hline
\end{tabular}

Vol. $57 \quad$ No. $3 \quad 2021$ 

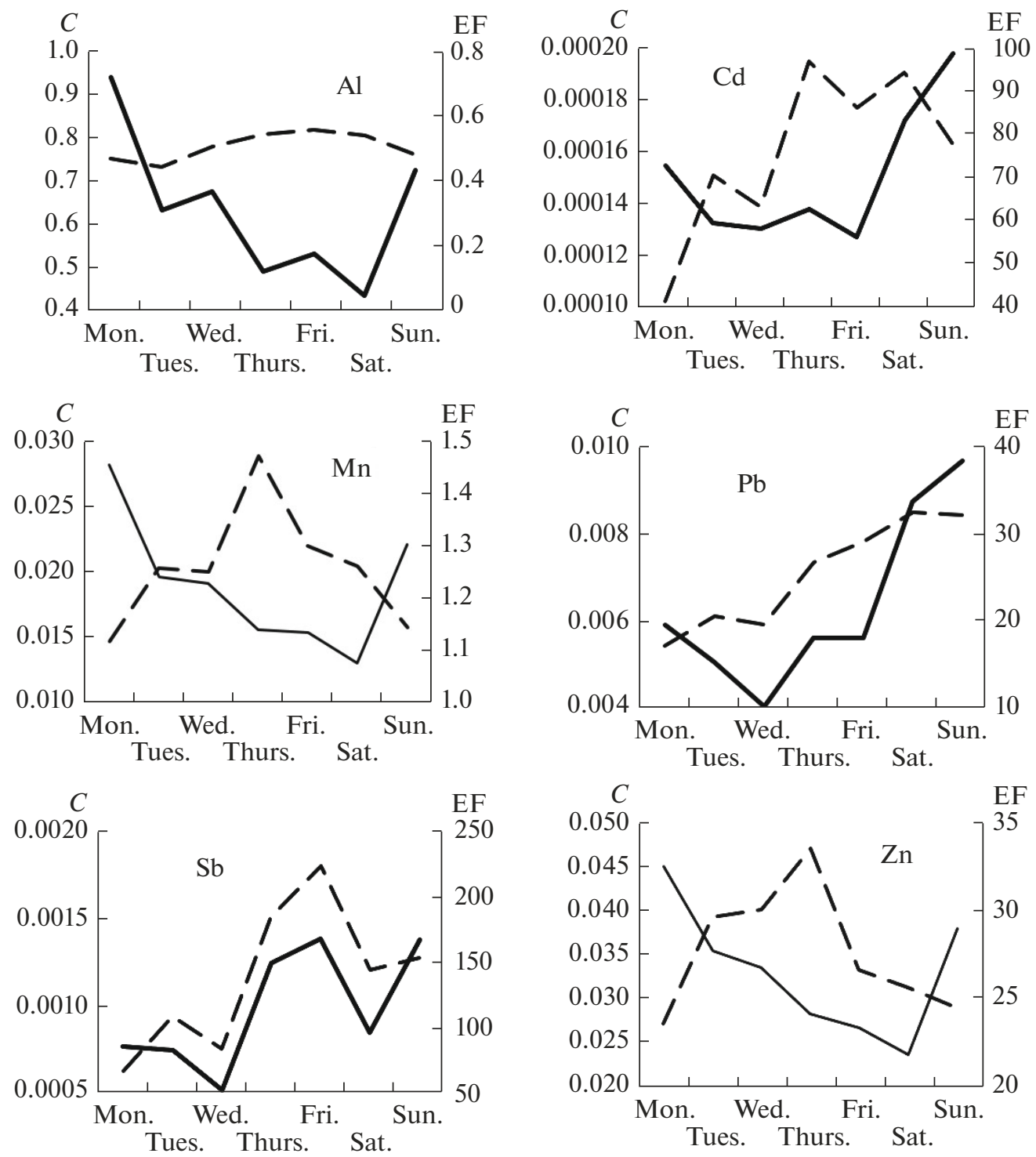

Fig. 8. Mean weekly relations between concentration $C\left(\mu \mathrm{m} / \mathrm{m}^{3}\right.$, solid line) and EF (dashed line) for different elements. The coefficients of correlation (for all 40 samples under consideration) between $C$ and $\mathrm{EF}$ are below zero for $\mathrm{Al}, \mathrm{Mn}$, and $\mathrm{Zn}$ and above zero for $\mathrm{Cd}, \mathrm{Sb}$, and $\mathrm{Pb}$.

Restrictive measures taken to prevent the spread of the covid infection and its related disinfection of the surface layers of soil, roads, courtyards, and streets were bound to affect the elemental composition of aerosol in Moscow in spring 2020. In particular, a decrease in the anthropogenic load could lead to variations in the ratio between masses of terrigenous and anthropogenic elements in aerosols, and the daily repeated washing and moistening of streets could decrease the level of aerosol pollution in the atmospheric surface layer in the daytime and affect the mean content of aerosol. However, the short data series under consideration does not allow one to reliably determine these effects. To find reliable variations in the aerosol composition, it is necessary to compare the results with data obtained in other seasons (to take into account intra-annual variations) and other years (without restrictive and disinfective measures).

\section{CONCLUSIONS}

It has been found that the physicochemical parameters of the near-surface air aerosol in Moscow depend strongly on both synoptical and meteorological conditions, which was especially pronounced in the spring of 2020 under conditions of decreased anthropogenic load during restrictive measures to prevent the spread of coronavirus infection. The daily mean concentrations of both $\mathrm{PM}_{10}$ and $\mathrm{PM}_{2.5}$ particles and 65 chemical elements under consideration did not exceed the MPCs for residential areas, except for the $\mathrm{PM}_{10}$ con- 

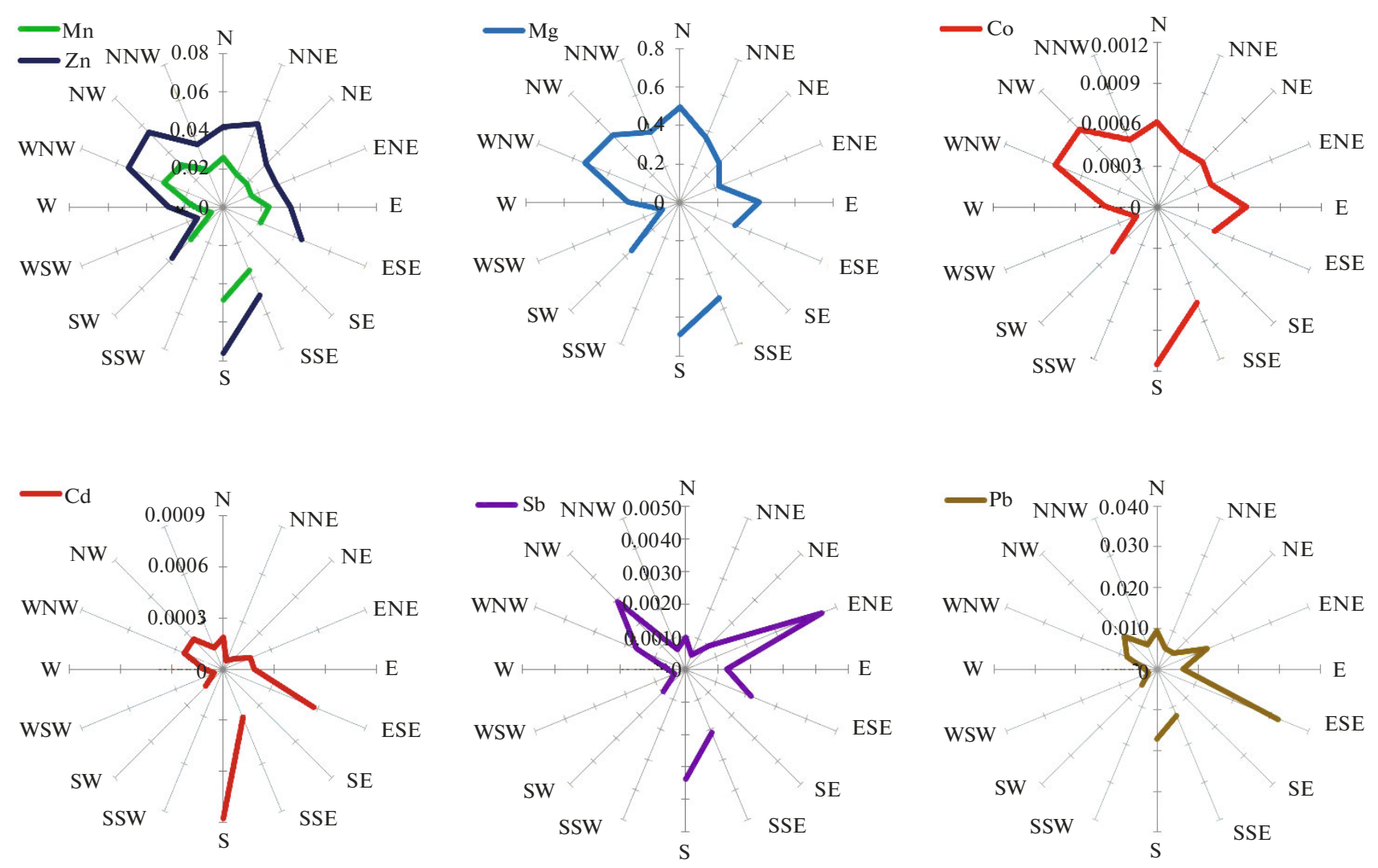

Fig. 9. Wind direction dependences of the concentrations $\left(\mu \mathrm{m} / \mathrm{m}^{3}\right)$ of some elements: the top diagrams are for GDEs and THMs and the lower diagrams are for AHMs. No day with mean winds of both southeast and south-southwest directions was observed within the period under consideration.

centrations observed on March 27-29 during an episode of increased air pollution in the city.

In late March 2020, the anomalously high mass concentrations of different particle fractions and all elements accumulated in aerosols were caused by unfavorable meteorological conditions; the anticyclone dominating over the Moscow region brought air masses from neighboring regions with biomass fires. For the rest of the time, in April 2020, the variability of the atmospheric aerosol composition was also caused mainly by natural factors. The highest increase in the total mass concentration of aerosols and contents of chemical elements contained in them was observed under anticyclonic conditions with calm or light winds of both south and south-southeast directions.

Data obtained from the analysis of correlations between the concentrations and enrichment factors of the elements supported the anthropogenic/local origin of some heavy metals ( $\mathrm{Cd}, \mathrm{Sb}, \mathrm{Pb}, \mathrm{Se}$, and $\mathrm{Th}$ ) and the terrigenous/global origin of elements such as $\mathrm{Mn}$, $\mathrm{Mg}, \mathrm{Zn}, \mathrm{Co}, \mathrm{Fe}, \mathrm{Al}$, and $\mathrm{Cr}$ in surface aerosol in Moscow in the spring of 2020. Some elements (S, P, K, Na, $\mathrm{Ca}, \mathrm{Ni}, \mathrm{Cu}, \mathrm{Mo}, \mathrm{Sn}, \mathrm{W}, \mathrm{Bi}$, and $\mathrm{U}$ ), for which no reliable correlations between their concentrations and enrichment factors have been determined, apparently originate from both natural and anthropogenic sources, whose contributions are comparable with each other and compete on different days.

The initial results obtained from the study of weekly variations in the concentrations of chemical elements in surface aerosol in the Moscow megacity show the variability of its relative elemental composition on different days of the week, which may be caused not only by natural factors, but also by effects of both local and regional sources. The influence of meteorological conditions, whose variations also had a characteristic period of about a week, was manifested not only in the variability of mass concentrations of aerosol particles of different sizes, but also in the weekly cycle of their elemental composition. Under anticyclonic conditions, at higher air temperatures and low humidity, aerosol particles accumulated in the atmospheric surface layer, and, upon a pressure drop and an increase in relative air humidity, the atmosphere is purified due to washout by precipitation or coagulation and the precipitation of aerosol particles onto the underlying surface. To reliably separate the effects of aerosol sources and meteorological parameters on the formation of the weekly cycle of the 
elemental aerosol composition, further more intensive studies will be carried out to compare observational data obtained through longer periods in different seasons.

\section{ACKNOWLEDGMENTS}

We thank the organizers of the NOAA ARL website for providing free access to their data and we are grateful to a reviewer for helpful remarks.

\section{FUNDING}

This work was supported by the Russian Foundation for Basic Research, project nos. 19-05-00352 and 19-05-50088.

\section{REFERENCES}

1. J. H. Seinfeld and S. N. Pandis, Atmospheric Chemistry and Physics: from Air Pollution to Climate Change (Wiley, New York, 2006).

2. K. Ya. Kondrat'ev, L. S. Ivlev, and V. F. Krapivin, Atmospheric Aerosols: Properties, Formation, and Impacts. From Nano- to Global Scales (VVM, St. Petersburg, 2007) [in Russian].

3. A. S. Ginzburg, D. P. Gubanova, and V. M. Minashkin, "Influence of natural and anthropogenic aerosols on global and regional climate,” Russ. J. Gen. Chem. 79 (5), 2062-2070 (2008).

4. W. H. Schroeder, M. Dobson, D. M. Kane, and N. D. Johnson, "Toxic trace elements associated with airborne particulate matter: A review," J. Air Pollut. Control Assoc. 37 (11), 1267-1285 (1987).

5. P. E. Rasmussen, "Long-range atmospheric transport of trace metals: the need for geoscience perspectives," Environ. Geol. 33 (2-3), 96-108 (1998).

6. A. Kh. Ostromogil'skii and V. A. Petrukhin, "Heave metals in the atmosphere: sources and methods for their impact assessment," in Monitoring of the Background Pollution of Natural Environments (Gidrometeoizdat, Leningrad, 1984), vol. 2, pp. 56-70 [in Russian].

7. L. A. Barrie, "Aspects of atmospheric pollutants origin and deposition revealed by multielemental observations at a rural location in Eastern Canada," J. Geophys. Res. 93 (D4), 3773-3788 (1988).

8. W. Maenhaut, P. Cornille, J. M. Pacyna, and V. Vitols, "Trace element composition and origin of the atmospheric aerosol in the Norwegian Arctic," Atmos. Environ. 23 (11), 2551-2569 (1989).

9. J. M. Pacyna, "Source inventories for atmospheric trace metals," in Atmospheric Particles, Ed. by R. M. Harrison and R. van Grieken (Wiley, Chichester, 1998), pp. 385423.

10. A. A. Vinogradova, "Anthropogenic pollutants in the Russian Arctic atmosphere: Sources and sinks in spring and summer," Atmos. Environ. 34 (29-30), 5151-5160 (2000).

11. P. Salvador, B. Artíñano, C. Pio, J. Afonso, M. Legrand, H. Puxbaum, and S. Hammer, "Evaluation of aerosol sources at European high altitude background sites with trajectory statistical methods," Atmos. Environ. 44, 2316-2329 (2010).

12. D. P. Gubanova, T. M. Kuderina, O. G. Chkhetiani, M. A. Iordanskii, Yu. I. Obvintsev, and M. S. Artamon- ova, "Experimental studies of aerosols in the atmosphere of semiarid landscapes of Kalmykia. 2. Landscape-geochemical composition of aerosol particles," Izv., Atmos. Ocean. Phys. 54 (10), 1430-1448 (2018).

13. A. V. Trefilova, M. S. Artamonova, T. M. Kuderina, D. P. Gubanova, K. A. Davydov, M. A. Iordanskii, E. I. Grechko, and V. M. Minashkin, "Chemical composition and microphysical characteristics of atmospheric aerosol over Moscow and its vicinity in June 2009 and during the fire peak of 2010," Izv., Atmos. Ocean. Phys. 49 (7), 765-778 (2013)

14. S. F. Abdullaev, V. A. Maslov, B. I. Nazarov, U. Madvaliev, and T. Davlatshoev, "The elemental composition of soils and dust aerosol in the south-central part of Tajikistan," Atmos. Oceanic Opt. 28 (2), 347-358 (2015).

15. M. S. Artamonova, D. P. Gubanova, M. A. Iordanskii, V. A. Lebedev, L. O. Maksimenkov, V. M. Minashkin, Y. I. Obvintsev, and O. G. Chkhetiani, "Variations of the aerosol concentration and chemical composition over the arid steppe zone of Southern Russia in summer," Izv., Atmos. Ocean. Phys. 52 (8), 769-783 (2016).

16. A. A. Vinogradova, I. P. Malkov, A. V. Polissar, and N. N. Khramov, "Elemental composition of surface atmospheric aerosol in the Russian Arctic region," Izv. Akad. Nauk: Fiz. Atmos. Okeana 29 (2), 164-172 (1993).

17. A. A. Vinogradova, I. P. Malkov, and A. V. Polissar, "Investigation of the Arctic aerosol pollution," in Optical Monitoring of the Environment (SPIE, 1993), Vol. 2107, pp. 203-211.

18. V. Shevchenko, A. Lisitzin, A. Vinogradova, and R. Stein, "Heavy metals in aerosols over the seas of the Russian Arctic," Sci. Total Environ. 306, 11-25 (2003).

19. K. P. Kutsenogii and P. K. Kutsenogii, "Aerosols in Siberia. Results of seven-year investigations," Sib. Ekol. Zh., No. 1, 11-20 (2000).

20. M. Yu. Arshinov, B. D. Belan, T. M. Rasskazchikova, and D. V. Simonenkov, "Impact of the town of Tomsk on the chemical composition and size distribution of atmospheric aerosol in the surface layer," Opt. Atmos. Okeana 21 (6), 487-491 (2008).

21. V. Yu. Bortnikov, V. I. Bukatyi, I. V. Ryabinin, and G. A. Semenov, "Microphysical parameters and elemental composition of atmospheric aerosol in the town of Barnaul in 2006-2008," Izv. Altai. Gos. Univ. 61 (1), 106-110 (2009).

22. F. Ya. Rovinskii and V. A. Petrukhin, "Background content of metals in the atmospheric surface layer," in Nuclear Physics Methods for Environmental Analysis and Control (Gidrometeoizdat, Leningrad, 1985), pp. 8-19 [in Russian].

23. V. N. Lukashin and A. N. Novigatsky, "Chemical composition of aerosols in the near-water surface atmospheric layer of the Central Caspian Sea in the winter and autumn of 2005," Oceanology (Engl. Transl.) 53 (6), 727-738 (2013).

24. A. A. Volokh and M. G. Zhuravleva, "Assessment of anthropogenic air pollution in Moscow," Izv. Akad. Nauk: Fiz. Atmos. Okeana 30 (2), 182-188 (1994).

25. B. I. Ogorodnikov, A. K. Budyka, V. I. Skitovich, and A. V. Brodovoi, "Characteristics of aerosols in the boundary layer of the atmosphere over Moscow," Izv., Atmos. Ocean. Phys. 32 (2), 149-157 (1996).

26. A. V. Andronova, M. A. Iordanskii, A. V. Trefilova, V. A. Lebedev, V. M. Minashkin, Yu. I. Obvintsev, M. S. Artamonova, and I. G. Granberg, "Comparative 
analysis of pollution of the surface atmospheric layer in such megalopolises as Moscow and Beijing," Izv., Atmos. Ocean. Phys. 47 (7), 819-827 (2011).

27. D. P. Gubanova, I. B. Belikov, N. F. Elansky, A. I. Skorokhod, and N. E. Chubarova, "Variations in PM2.5 surface concentration in Moscow according to observations at MSU meteorological observatory," Atmos. Oceanic Opt. 31 (12), 290-299 (2018).

28. D. P. Gubanova, M. A. Iordanskii, P. P. Anikin, T. M. Kuderina, A. I. Skorokhod, and N. F. Elansky, "Elemental composition and mass concentration of near surface aerosols in Moscow region during unusual weather conditions in the fall 2019," in Proc. SPIE: 26th International Symposium on Atmospheric and Ocean Optics, (Moscow, 2020), 115604M. https://doi.org/10.1117/12.2575578

29. D. P. Gubanova, N. F. Elansky, A. I. Skorokhod, T. M. Kuderina, M. A. Iordansky, N. V. Sadovskaya, and P. P. Anikin, "Physical and chemical properties of atmospheric aerosols in Moscow and its suburb for climate assessments," IOP Conf. Ser.: Earth Environ. Sci., 606, 012019 (2020). https://doi.org/10.1088/1755-1315/606/1/012019

30. D. V. Vlasov, N. S. Kasimov, and N. E. Kosheleva, "Geochemistry of road dust (Eastern District of Moscow)," Vestn. Mosk. Univ., Ser. 5: Geogr., No. 3, 2333 (2014).

31. N. E. Kosheleva, M. F. Dorokhova, N. Yu. Kuz'minskaya, A. V. Ryzhov, and N. S. Kasimov, "Road transport impact on the ecological state of soils in the western administrative district of Moscow," Vestn. Mosk. Univ., Ser. 5: Geogr., No. 2, 16-27 (2018).

32. N. S. Kasimov, D. V. Vlasov, and N. E. Kosheleva, "Enrichment of road dust particles and adjacent environments with metals and metalloids in Eastern Moscow," Urban Clim., 32, 100638 (2020). https://doi.org/10.1016/j.uclim.2020.100638

33. V. K. Karandashev, A. N. Turanov, T. A. Orlova, A. E. Lezhnev, S. V. Nosenko, N. I. Zolotareva, and I. R. Moskvina, "The use of inductively coupled plasma mass spectrometry in elemental analysis of environmental objects," Zavod. Lab., Diagn. Mater. 73 (1), 12-22 (2007).

34. https://rp5.ru.

35. https://www.windy.com/ru.
36. R. R. Draxler and G. D. Hess, "An overview of the HYSPLIT 4 modeling system for trajectories, dispersion, and $\bar{d}$ eposition,” Aust. Met. Mag. 47, 295-308 (1998).

37. https://fires.ru.

38. https://mosecom.mos.ru/spiridonovka/.

39. D. P. Gubanova, A. I. Skorokhod, V. M. Minashkin, and M. A. Iordanskii, "Variability of surface aerosol in Moscow under decreased anthropogenic load in spring 2020," in Turbulence, Dynamics of the Atmosphere and Climate. All-Russian Conference Devoted to the Memory of Academician Aleksandr Mikhailovich Obukhov. Collection of Presentation Abstracts (Fizmatkniga, Moscow, 2020), p. 108 [in Russian].

40. https://www.arl.noaa.gov.

41. J. B. Milford and C. I. Davidson, "The sizes of particulate trace elements in the atmosphere: A review," J. Air Pollut. Control Assoc. 35 (12), 1249-1260 (1985).

42. V. V. Ivanov, Ecological Geochemistry of Elements: Reference Book in 6 Volumes, Vol. 2: Major p-Elements (Nedra, Moscow, 1994) [in Russian].

43. A. I. Perel'man and N. S. Kasimov, Landscape Geochemistry (Astreya-2000, Moscow, 1999) [in Russian].

44. V. A. Petrukhin, L. V. Burtseva, L. A. Lapenko, T. B. Chicheva, V. A. Vizhenskii, and I. V. Komardenkova, "Background content of microelements in natural environments according to world data. Notification 5," in Monitoring of the Background Pollution of Natural Environments (Gidrometeoizdat, Leningrad, 1989), Vol. 5, pp. 4-27 [in Russian].

45. N. S. Kasimov, Ecogeochemistry of Landscapes (IP Filimonov M.V., Moscow, 2013) [in Russian].

46. V. V. Dobrovol'skii, Biogeochemistry of World Soils: Selected Works (Nauchnyi mir, Moscow, 2009) [in Russian].

47. H. A. Panofsky and G. W. Brier, Some Applications of Statistics to Meteorology (University Park, Pennsylvania, 1968; Gidrometeoizdat, Leningrad, 1972) [in Russian].

48. J. M. Pacyna, A. Bartonova, P. Cornille, and W. Maenhaut, "Modeling of long-range transport of trace elements. A case study," Atmos. Environ. 23 (1), 107-114 (1989).

Translated by B. Dribinskaya 